\title{
THE PSYCHOLOGICAL STATUS OF PHONOLOGICAL ANALYSES
}

This paper casts doubt on the psychological relevance of many phonological analyses. There are four reasons for this: 1) theoretical adequacy does not necessarily imply psychological significance; 2) most approaches are nonempirical in that they are not subject to potential spatiotemporal falsification; 3 ) phonological analyses are established with little or no recourse to the speakers of the language via experimental psychology; 4) the limited base of evidence which most analyses are founded on is further cause for skepticism.

Although most theoretical analyses cannot be considered psychologically significant, they are viewed as the first step in arriving at psychologically valid analyses. Once phonological analyses are based on empirical evidence which is obtained by psychological means, their psychological validity will be less often challenged.

0 . Introduction. The psychological status of linguistic analyses was a much debated topic among what could be termed 'practicing linguists' during the 1970s. In the last decade and a half, by contrast, the subject seems to have been largely abandoned by 'practicing linguists' and continued mainly by philosophers of language. At first glance, it could appear that this decrease in attention to the subject is due to the fact that the matter was resolved, at least from the viewpoint of 'practicing linguists.' However, this is not at all the case. Instead of resolving the debate, researchers seem to have put it on hold while they turned their attention to the newly emerging theories of the day (e.g. autosegmental phonology, optimality theory etc.). This purpose of this paper is to renew interest in this important issue by examining the status of phonological analyses as psychologically pertinent ones.

1. The psychological status of phonological rules. Prior to the advent of generative linguistics, linguistics in the United States was decidedly behavioristic. The behaviorists, led by Bloomfield, felt that the psyche was an unobservable entity, and as such, any arguments that were psychological in nature were unscientific, and therefore, rejected. It is Chomsky who is principally responsible for resurrecting and propagating the idea that linguistic analyses are not mere descriptions of linguistic data. He believes that they represent the speaker's actual underlying knowledge of the language, which he terms competence. According to Chomsky, linguistics is a 'branch of cognitive psychology' (1972: 1). More specifically, he asserts that linguistic rules and principles are psychologically real (1980a: 48). 
Many contemporary phonological analyses follow Chomsky in asserting psychological relevance. For example, it is extremely common for an analysis to begin by claiming that it has as its goal, to provide a descriptively adequate account of some linguistic phenomenon. By definition, a descriptively adequate analysis is thought to describe the 'linguistic intuition of the native speaker' (Chomsky 1964: 28-9). Therefore, an analysis which claims descriptive adequacy also purports to be psychologically valid, and not to merely describe the language data.

The issue of the psychological status of phonological theories centers on phonological rules. Once a generalization has been formalized into a rule or system of rules, what exactly is meant when it is claimed that the rule or system of rules is psychologically real? There are two senses in which grammars may be considered psychologically real. Cutler (1979: 79) defines them in this way:

In the strong sense, the claim that a particular level of linguistic analysis $\mathrm{X}$, or postulated process $\mathrm{Y}$, is psychologically real implies that the ultimately correct psychological model of human language processing will include stages corresponding to $\mathrm{X}$ or mental operations corresponding to Y. The weak sense of the term implies only that language users can draw on knowledge of their language which is accurately captured by the linguistic generalization in question. (see also Steinberg 1975: 218-20)

The strong sense implies a close relationship between the way a theoretical analysis works out on paper, and the internalized representations, and mental processes speakers possess. On the other hand, the weak sense involves little correspondence between theoretical constructs and psychological mechanisms. Accordingly, if an analysis produces the same output as do the speakers of the language, then in a limited way, it may claim to have achieved psychological validity (Rischel 1978: 442).

Rules are often spoken of as if they were algorithmic operations or mental processes. If this were true then they would be candidates for attaining reality in the strong sense. However, though they are often spoken of in this way, they are usually defined in terms of speakers' intuitions, tacit knowledge or underlying representations, and not in terms of mental processes. Since they are defined in these terms, they cannot be considered psychologically valid in the strong sense. As a result, one must speak of the psychological reality of a rule or representation in Cutler's weak sense. This means that what is potentially real in an analysis is not the formal notation with its derivations, rules and orderings. What is real is 'the function that these constructs serve to specify' (Matthews 1991: 197), or the contents of the rules (Rischel 1978: 442).

2.0. Reasons for doubting the psychological reality of phonological analyses in the weak sense. In principle, an analysis of a given linguistic phenomenon may achieve psychological significance in the weak sense of the term. However, there are even reasons for doubting the psychological reality of an analysis in the weak sense also. These fall into four categories: 1) the 'truth equals reality' issue, 2) the empirical status of phonological analyses, 3) the question of autonomous versus nonautonomous methodology, and 4) the narrow base of evidence. Each of these will be discussed in this section. 
2.1. Truth equals reality. One of the most common criticisms of linguistic analyses is that there is insufficient justification that they are more than mere descriptions, but actually have some kind of bearing on human language faculties. The objection is that a detailed, rigorous, or sophisticated description of a linguistic phenomenon does not necessarily indicate that the phenomenon has any relevance to linguistic cognition. This sentiment has been expressed by a number of linguists (e.g. Botha 1971; Derwing, Prideaux, and Baker 1980; Goyvaerts 1978: 12; Lass 1976b; Morin 1988; Skousen 1989).

In response to such charges, Chomsky has attempted to explain the justification for assigning mentalistic status to grammatical constructs. As far as he is concerned, linguistics achieves this in the same way empirical sciences such as physics do, the only difference being that researchers in physics deal with physical entities while linguists 'are keeping to abstract conditions that unknown mechanisms must meet' (Chomsky 1976: 9).

Linguistic theories typically include entities such as parameters, orderings, and rules, none of which are directly observable. This is analogous to the way quantum physics includes entities such as quarks, or psychology includes concepts such as the superego or motivation. Since these entities are not directly observable, their existence is motivated entirely on indirect evidence. Mohanan's (1986: 185) statement illustrates argumentation based on indirect evidence:

It does not make sense to ask, 'does the unconscious mind really exist?' When faced with this question, what the psychologist does is to produce a range of facts which the notion of the unconscious mind can account for. Therefore, the question ought to be, 'What kind of evidence do we have for assuming the theoretical entity 'unconscious mind'?' Similarly, it does not make sense to ask if syllables and segments really exist in the human mind; instead, we should ask what kind of evidence we have to assume that they are part of the mental representations of language users.

According to this line of reasoning, if a theoretical entity aids in describing the structures or distributional patterns of a language, then there is ample evidence that the entity exists.

Chomsky protests that the reality of theoretical linguistic entities is often questioned, while the entities of other sciences are not. In linguistics, as well as in other sciences, theoretical entities are postulated because the data and evidence which have been gathered to date support their existence. In any science, once all the evidence has been gathered, and the best possible theory based on that evidence has been put forth, the theory is not only deemed true within its theoretical domain, but it is also considered to reflect reality as well (Chomsky 1980a: 190-1; see also Chomsky 1986: 252-7).

If one assumes that there is no distinction between the best possible analysis of some linguistic phenomenon, and the psychological relevance the analysis may have for language speakers, it would necessarily follow that all aspects of a 'correct' analyses are also aspects of a psychologically significant one also. Harmon (1980: 21-2) explains why this is not necessarily the case: 
But, given any theory we take to be true, we can always ask what aspects of the theory correspond to reality and what aspects are mere artifacts of our notation. Geography contains true statements locating mountains and rivers in terms of longitude and latitude without implying that the equator has the sort of physical reality the Mississippi River does. (see also Matthews 1991: 196)

The stance taken by Chomsky leaves no room for some elements of the theory to be real and for others to be simply artifacts of the formal notation used within a given theoretical framework. This is surely an untenable position, and one which Chomsky later abandoned, admitting that 'there is a question of physical (or psychological) reality apart from truth in a certain domain ...' (1980b: 45). In other words, the search for linguistic realities and psychological realities belong to separate domains (see Yngve 1986).

The question which now arises is this: If constructs belonging to the best analysis of a linguistic phenomenon are not necessarily real, why are constructs belonging to other sciences (e.g. atoms, quarks, black holes) considered real by the same token? The answer is simply that generative linguistics is a fundamentally different type of science than is, for example, physics (Katz 1981, 1985; Lass 1984: 104). In the next section, I will argue that the theories, constructs, and methodologies of physics are empirical, while much of what is done in contemporary phonology is nonempirical.

2.2. Empiricality. Chomsky charges that linguistics is confronted with issues which other sciences are not forced to deal with. More specifically, linguists are often asked to produce 'more convincing evidence' that their theoretical constructs are real. Yet, the evidence that scientists working in the hard sciences produce in favor of a theoretical entity is often accepted at face value (Chomsky 1980a: 22). This difference is due to the fact that people have more confidence in the physical reality of a theoretical construct which belongs to an empirical science, than they than they do in one pertaining a nonempirical science. Much of what is done in contemporary phonology falls into the latter category.

Quite a large body of literature exists which demonstrates that much of what is done in linguistic analyses is nonempirical in nature, and should therefore be grouped together with other nonempirical sciences such as formal logic, pure mathematics, and philosophy (Botha 1971, 1973; Derwing 1973; Hall 1987; Itkonen 1976a, 1978a, 1978b, 1983; Katz 1981, 1985; Katz and Postal 1991; Lass 1976; Ringen 1975; and Steinberg 1975; Yngve 1986). ${ }^{1}$ There are several reasons cited for making this classification. One of the most common has to do with falsifiability.

2.2.1. Falsifiability. Falsifiability is the criterion which distinguishes between empirical theories and nonempirical theories (Popper 1968: 27-48). In order for a theory to be empirical it must be potentially falsifiable, experimentation being one of the chief means of falsification. Theories which can be potentially falsified possess a sense of 
concreteness and reality which is lacking in theories for which there is no counterevidence or other possible refutation.

One theoretical notion which is not subject to potential falsification is that of the ideal speaker-hearer. Many analyses claim to describe the phonological system of an ideal speaker-hearer. It should be clear that a concept, such as the ideal speaker-hearer, is useful in constructing descriptive grammars. In the original stages of theory building, a model such as the ideal speaker-hearer is often proposed which excludes some factors for simplicity's sake. The model of the ideal speaker-hearer does not incorporate factors such as individual differences, slips of the tongue, and ambient noise, in an attempt to devise a simple yet general model of language. This, of course, is no different than what a physicist does when excluding friction as a factor in a model of what happens to objects as they move through space. The difference is that at some point, the physicist factors the effect of friction back into the theory.

What ultimately makes the ideal speaker-hearer unfalsifiable, is that the factors which are originally omitted in order to simplify the model are never reincorporated. In most phonological analyses, the model language of the ideal speaker-hearer, void of all real-life variables, is in itself the object of study. Therefore, it is not subject to possible falsification (Hall 1987: 38; Prideaux 1980: 247; Wheeler 1980: 77-8). No evidence of any kind could possibly falsify what the phonological system of an ideal speaker-hearer may or may not contain. This is true because the ideal speaker-hearer is a convenient fiction whose mental grammar is not subject to inspection.

What constitutes the grammar of an idealized speaker-hearer is a perfectly legitimate, as well as scientific realm of enquiry, as Carr (1990), Katz (1981, 1985), and Katz and Postal (1991) have demonstrated. Pedagogical grammars, for example, describe an ideal state of affairs supposedly shared by all speakers of a given language. However, it is the supposition that all elements of such a grammar necessarily have correlations to the grammars of actual speakers which leads to skepticism (Derwing 1980: 173). This is not to deny the possibility that some aspects of the ideal speaker-hearer's grammar may very well relate to aspects of the mental grammar of actual speakers. However, exactly which aspects are, and which aspects are not psychologically real, is indeed an empirical question, the answer to which should not be determined on the basis of a priori assumptions nor nonempirical evidence.

The distinction which is often made between competence and performance has been accused of serving to immunize the analyses from falsification. Competence is defined as a speaker's knowledge of language, while performance is the use of that knowledge (Chomsky 1980a: 205). Competence is an idealized concept which comprises the system of rules which are thought to underlie a speaker's ability to produce and understand language. Performance is made up of specific utterances. Unlike competence it includes errors.

The insulating effect that the competence/performance distinction has on theoretical analyses is clearly seen in the following example: Suppose that two subjects react in a different manner to a question in a psycholinguistic experiment. One could say that 
the subjects have the same underlying knowledge of the language (competence), but that the experimental design was responsible for the differences. That is, that something in the experiment kept the subjects' reactions from reflecting their competence. Remember that competence is idealized in that it is free from errors and extra-linguistic influences, while performance includes errors. Therefore, it could be argued that the experiment must have measured performance, and not competence. An analysis which claims to describe the linguistic competence of the subjects would be unaffected by the differing responses given by each subject since the results of the experiment would only be indicative only of the subjects performance (See Derwing 1983: 66; Wheeler 1980: 78-90).

The question of where competence stops and performance begins is also difficult, if not impossible to determine. Any time an utterance is made, whether in the laboratory or in spontaneous speech, it necessarily involves both competence as well as performance. That is, there is no such thing as 'pure competence' unfettered by performance factors (Stemberger 1994; Wheeler 1980: 67; Zimmer 1969: 320). Competence cannot be produced alone and uninfluenced by performance. Therefore, since it is not subject to inspection, it is does not lend itself to possible refutation.

It must be stressed that the fact that few phonological analyses meet the requirement of falsifiability, has no bearing on whether or not they are good nonempirical analyses, only that they are not empirical. As such, they may be validated or refuted in the same way a philosophical argument is. According to Itkonen (1976a: 15-6), the nonempirical linguist and the logician have a similar goal:

to generate all and only intuitively valid formulae: insofar as they fail to do this, their systems are (nonempirically) falsified ... not by reference to some specific spatiotemporal occurrences, but showing that it does not capture the concept which it tries to capture. (See also Carr 1990: 66; Kac 1992: 39; Linell 1976: 84-5)

In a sense, nonempirical theories are falsified by one type of data, and empirical ones by another. Clearly, phonological theories are not usually judged on the basis of spatiotemporal data, but on the degree to which they correctly capture the phonological system of the language in question.

2.2.2. Spatiotemporality. In addition to being falsifiable, empirical theories must deal with events, activities or processes which take place in time, and/or across space (Itkonen 1978: 80; Popper 1968:102-3). This means that the falsification of such theories must be done on the basis of events or actions which take place across time and/or space. Nonempirical theories, on the other hand, either do not deal with spatiotemporal events, or do deal with them, but are formulated in such a way that they cannot be falsified by recourse to spatiotemporal events (Itkonen 1978: 155).

There is a relationship between a theory's spatiotemporal falsifiability and its reality. A theory which can be proved or disproved on the basis of spatiotemporal events possesses a sense of tangibility and concreteness. This is because events which are considered real (as opposed to abstract) take place in time and space. This same sense of 
tangibility is missing in a theory for which there are no spatiotemporal manifestations, or which eludes possible falsification.

Remember that the constructs and operations of most phonological theories are not thought to model the actual steps or processes utilized by actual speakers in producing and comprehending language. Instead, they represent the idealized language of an ideal speaker-hearer. Idealizations are a fact of life in all sciences. However, any idealized state of affairs is expected to come close to reality. Unfortunately, in many instances, the same cannot be said of idealizations in many aspects of linguistic theory (Bresnan and Kaplan 1982: xxiii). This is simply because theories do not profess to relate to actual spatiotemporal events, which prompts the question: 'What kind of reality can be ascribed to the notion of rule whose mental existence is not open to introspection and whose operations are ordered in non-real time?' (Derwing and Skousen 1989: 54). The answer, of course, is that such operations are purely notational or formulaic (Steinberg 1975: 246-7). Therefore, they fall outside the realm of empirical science, and into the realm of nonempirical science. A good case may be made for the reality of theoretical entities which are demonstrable by reference to spatiotemporal events. But by the same token, the reality of theoretical entities which are not related to spatiotemporal events is highly speculative.

In the above discussion, several reason have been given for classifying many phonological theories as a nonempirical. Some have reacted unfavorably to any suggestion that linguistics is less than empirical, which is most probably due to the fact that 'the word empirical has become so prestigious that it has blinded linguists to the respectability of non-empirical theories' (Lass 1976a: 217). The frequent, almost hackneyed use of the word 'empirical' in the literature, suggests a belief that a science becomes empirical, or that evidence becomes empirical, by mere denomination, and not by conforming to empirical criteria.

2.3. Methodology: Autonomous versus nonautonomous. The nonempirical status of many analyses is one reason that claims to psychological relevance are often questioned. Another reason is that most analyses are carried out in almost complete isolation from the speakers of the language themselves. A number of linguists have suggested that there are two distinct types of linguistics, each with a different methodology. These approaches will be referred to as autonomous and nonautonomous approaches. In this section, the reasons why there is so much doubt as to any psychological claim which is arrived at by autonomous methods is discussed.

At this point, it will be helpful to define autonomous and nonautonomous linguistics. Kac (1974: 42) defines autonomous linguistics as a field of study which attempts to produce psychologically significant theories without performing psychological experiments. It is the study of language structure in isolation from the pragmatic environment in which speech occurs, and without recourse, (or at most with only minimal recourse), to actual speakers. It involves the study of the patterns, alternations, and structures that are found to exist in linguistic data. It is a metaphysical or philosophical realm of inquiry which deals with axiomatizations about linguistic structure which 
'make it possible to deduce all true statements about the system from a small set of prior assumptions about its nature' (Kac 1974: 44).

Nonautonomous linguistics, on the other hand, is the study of language as an entity which is inseparable from the speakers of the language. It is the study of language with the methodological tools of the experimental cognitive psychologist. It attempts to determine what speakers know about their language, and how they actually process and store linguistic information.

The objection which is commonly raised against autonomous methodology is this (Derwing 1980): How can autonomous theories profess to be pertinent to the speaker's knowledge or manipulation of linguistic elements, if they are arrived at with little or no recourse to actual speakers, and are carried out as if human language were an entity separate from humans? Of course, an autonomous analysis may be considered to be potentially real in that it 'reflects a kind of abstract complexity with which somehow the human brain must cope' (Goyvaerts 1978: 12), but it does not necessarily spell out how the brain copes with it. Autonomous linguistics studies the structures which exist in languages. Therefore, it is a field of inquiry which is psychologically relevant in that the structure of a given language is what renders it 'capable of being learned and employed by speakers' (Kac 1974: 42). It does not, however, express what speakers actually know about the structures of their language, nor how they utilize them. Only nonautonomous analyses are justified in making the claim that they characterize speakers' actual, and not simply their potential, linguistic competence (Kac 1974: 42).

Although theories arrived at by autonomous methods may be useful and potentially real, they do have serious limitations. Phonologists who fail to fully incorporate the speakers of a language into a theory about the phonological system of those speakers, run the risk of treating language as an entity completely separate from humans; as a result, it becomes easy to confuse psychological reality with descriptive validity. As Black and Chiat note (1981: 42), it is a common practice to refer to an analysis as 'psychologically valid' when what is actually meant is that the analysis is 'linguistically valid' with no psychological substance intended.

Autonomous phonology has had tremendous success in discovering phonological structures, patterns, and generalizations which are to be found in language data. Because the data have been produced by humans, it is possible that humans have knowledge of, or utilize those structures, patterns and generalizations. However, their existence is not proof that speakers do use them, nor that they have knowledge of them. It only demonstrates that those structures and patterns are available to be potentially known or used. In order to determine what is actually known or utilized by the speakers, the focus of the research must turn back towards the speakers themselves.

It is highly possible that some patterns, structures and generalizations exist in a given language which speakers do not utilize or have knowledge of. A phonological structure may have arisen by chance, or be the result of a diachronic process which has long since died. Certain alternations may be due to purely articulatory or aerodynamic influences, and in that case, would neither be knowable nor psychological at all. The 
task of nonautonomous linguistics is to differentiate between those structures which possess potential psychological relevance, and those which have actual psychological relevance.

Of course, it should be noted that some analyses do include native speakers' intuitions about the correctness or incorrectness of linguistic structures. Certainly this is a step toward the development of a mentalistic theory of linguistics. However, the methodology used in gathering intuitions is frequently poor. Often, such analyses are founded solely on the intuitions of the very linguist who performs the analysis. A theory of psychology, based on data psychologists are able to glean from their own psyches, would surely be considered seriously methodologically flawed. ${ }^{2}$ The task of any scientist is to gather evidence in the most objective way possible, in order to be able to assert, with the utmost confidence, that the evidence is valid beyond the laboratory. A phonological analysis which center on the linguist's personal introspections about some phenomenon are suspect. Ohala (1990: 163) suggests that this is so because

The knowledge the linguist has about spoken forms, including historical derivational relationships between words, the morphemic structure of complex words, and the inductively-based knowledge of common cross-language sound patterns, is projected onto the mental grammar of linguistically-naive native speakers.

Any characterization of what constitutes the knowledge of the speakers of a language should ultimately come from linguistically naive speakers of the language.

Unfortunately, even studies which incorporate the intuitions of naive speakers are frequently methodologically weak. It is common for analyses to be based on the responses of only one or two subjects, which is far from a representative sample of a population. Very rarely do analyses founded on intuitions attempt to control for factors which may affect the internal or external validity of outcome, nor do they observe the procedures established and followed by other empirical sciences for determining the significance of their results statistically. The lack of sound psychological methodology is what prompts Derwing (1979: 117) to conclude that

The so-called 'Chomskyan Revolution' may well have entailed a terminological re-orientation in the direction of the psychologization of linguistic jargon and the supposed domain of its interest and claims, [but] no corresponding methodological revolution accompanied these changes....

In summary, the psychological status of many phonological analyses is suspect simply because its methodology is not trusted. This does not imply that the autonomous approach should be eliminated, only that one should be skeptical of psychological conclusions arrived at by autonomous methods. It is necessary to draw a sharp line between nonautonomous and autonomous approaches, as well as between psychological and nonpsychological conclusions (Carr 1990: 34-38; Itkonen 1976b: 219).

2 In the classical movement of psychology, psychologists relied heavily on their own introspections. Later schools of psychology rejected this as methodologically flawed and subjective (Spence 1956:4-15). 
2.4. Evidence. One reason for questioning the psychological validity of many phonological analyses is that the evidence on which they are founded is almost exclusively internal evidence. Critics call for more external evidence, and charge that the external evidence which goes against a particular theory is overlooked, or rejected as irrelevant (Mohanan 1986: 185). An actual definition of what sorts of evidence fit into each category is essential.

Internal evidence is primarily drawn from the data gleaned from a corpus of utterances. It involves generalizations which are based on the surface regularities and alternations found in the language data, which spell out the distribution of linguistic structures, as well as what structures or elements are not found in a particular context. The internal evidence about the phonological system of a particular language consists of the phonetic and phonemic alternations which are found, as well as the restrictions which exist in the distribution of the phonological elements (Zwicky 1975: 154).

The major difference between internal and external evidence is that internal evidence comes from language used in unexceptional ways, such as the printed language, and careful, monitored speech. External evidence, on the other hand, may be thought of as evidence gathered from the actual use of language, especially its use in unusual and exceptional ways and situations (Campbell 1986: 171). Among other places, external evidence comes from language games, speech errors, intra-language borrowing, aphasia, spelling errors, historical change, stylistic variation, informant judgments, ${ }^{3}$ and of course, psycholinguistic experiments (Zwicky 1975: 154-5).

Some have thought that the two types of linguistic evidence correspond to two fields of linguistic inquiry. According to this view, internal evidence is relevant to an approach which has as its goal, to describe the structure of a language, without asserting that the resulting grammar has mentalistic import. On the other hand, a grammar which claims to be psychologically significant must not be founded on internal evidence alone, but must crucially include external evidence as well (Carr 1990: 34-38; Lass 1984: 214-5; Ohala 1990: 159-60; Wheeler 1980: 54). Itkonen's statement is representative of this sentiment (1978: 220-1):

It ought to be self evident that this psycholinguistic hypothesis must be tested on the basis of new, independent [read external] evidence provided, above all, by psycholinguistic experimentation, and not on the basis of those very same grammatical descriptions [read internal evidence] which, in the first place, gave rise to the psycholinguistic hypothesis in question.

The major point of contention is that the language internal evidence, which forms the basis for assuming the existence of a theoretical entity, may not at the same time, constitute proof of the existence of the entity in the psyches of the speakers of the language. Failure to make this distinction results in equating the phenomenon explained with the explanation of the phenomenon (Ohala 1990: 159). Or in other words, it is a 
case of elevating a linguistic description to the status of a psychological explanation (Black and Chiat 1981: 48).

Of course, this opinion is not shared by all linguists. For example, the assumption that certain kinds of evidence count as evidence for a good theory, while others count as evidence for the psychological validity of the theory is considered absurd by Chomsky (1980a: 107-8). What disturbs him is that linguistics is often asked to provide a new and different kind of evidence in order to prove its constructs are real, which is something that is not asked of researchers in other sciences. He gives the following analogy (1980a: 189-91).

When an astronomer hypothesizes that certain thermonuclear reactions occur in the sun's interior, s/he presents all the available evidence, and concludes that those reactions are physically real. Once all the available evidence has been gathered and interpreted, there is no evidence, short of physically exploring the sun's interior, which would entitle the astronomer to claim 'a higher order of physical reality' than before. However, linguists are often asked for a different, or better kind of evidence before the reality of their theories is accepted.

If the analogy between the astronomer and the linguist is extended, the reason why more evidence is called for becomes clear. Imagine that the astronomer almost exclusively admits only that evidence which can be gathered through a telescope. S/he is convinced that observations through the telescope provide the best evidence for proving true hypotheses about thermonuclear reactions in the sun. Furthermore, there are other means besides the telescope available for gathering information about the sun. The astronomer unhesitatingly states that these other methods may be very useful and condones their use, but makes no effort to use them him/herself in order to gain further insight. Moreover, when other astronomers present evidence which these other methods have provided, the astronomer either deems them irrelevant, or accepts only the evidence which corroborates the evidence s/he has obtained through the telescope. Would it be unusual or unwarranted under these circumstances, for scientists to question the reality of the astronomer's theory, and ask for more evidence?

The fact that a large body of evidence is commonly overlooked in the formation of phonological theories, has prompted some to group the overlooked types of evidence together (external), and to contrast them with the more commonly used types of evidence (internal). Chomsky is correct when he asserts that once all the evidence has been gathered, and it supports a given theoretical construct, one may safely conclude that the construct is real. What many see, however, is that many theories cannot presume reality because all the evidence is not considered.

When phonologists are asked for more evidence, they are, in effect, being asked to include the evidence obtained by other means along with the evidence gathered through the 'telescope' (i.e. internal reconstruction). A true incorporation of all the available evidence does not, of course, mean that evidence of one type, or from one source, is accepted if it corroborates the theory, and if it does not, it is ignored. Unfortunately, this is precisely the manner in which external evidence is often treated (See Bertinetto 1992, 
for an example). Once both the internal and external evidence support a given theoretical entity, much more of a case may be made for the reality of the entity.

There is a further difficulty with making an analogy between the thermonuclear reactions in the sun and the linguistic knowledge of language speakers. The analogy exemplifies the widespread view that the only evidence, or at least the best evidence, is that which is obtained through observation. The thermonuclear reactions in the sun may only be studied by observation. They may not be manipulated under controlled circumstances, nor tested, nor experimented with. The same is not true of human language capabilities which lend themselves to methods other than passive observation-experimentation. Perhaps the reason that some make such a sharp distinction between internal and external evidence is that external evidence seems to be more telling of how language is actually manipulated, as well as what kinds of knowledge are drawn upon in order to produce and comprehend it.

Chomsky's position on the value of external evidence is somewhat inconsistent. On a number of occasions, he has asked that more and varied kinds of evidence, including experimental evidence, be admitted into the pool of linguistic evidence (1981: 9; 1986: 36-7). Yet, on another occasion, he questions the utility of certain experimental results (1982: 33). His low regard for external type evidence is clearly demonstrated below:

As an objection of a narrower sort, one can take it seriously as an argument that the evidential base is too narrow to carry conviction; one who believes this might ask what other kinds of evidence would strengthen or undermine the theories we are led to construct on the basis of the (not inconsiderable) evidence that we can now readily obtain. In practice, what has been produced along these lines has not been very informative, but certainly any improvement in this regard will be welcome. (1986: 260. Emphasis is mine)

In theory, Chomsky invites all kinds of evidence, but in practice he finds only a restricted kind of evidence truly compelling.

In section 2.1. it was seen that Chomsky originally held that there was no difference between the best theory, and the reality of the constructs proposed by the best theory. If this is correct, then it logically follows that there cannot be two distinct kinds of evidence: one which is better for proving the psychological relevance of a theory, and another which serves only to prove that the theory is true within its theoretical realm. This position is perfectly rational assuming that there is no difference between the best theory and psychological reality. However, Chomsky later conceded that one must sort out what elements of the best (i.e. true) theory are real, and which are artifacts of the theoretical notation. This concession would in turn, logically entail another concession, namely, that one kind of evidence may be more pertinent to the truth of a theory, while another may have more significance for the psychological reality of the theory. Unfortunately, this related concession has not yet been made by Chomsky (Botha 1989: 184$5)$.

However, others maintain that the dichotomy exists, and that external evidence offers more insight into the mind. According to this point of view, external evidence is vi- 
tal to discovering which of the potentially internalizable phonological structures are actually captured, and productively used by the speakers of a language (Campbell 1979: 77; Skousen 1975: 20-1). In this regard, Mohanan (1986: 58-9) states:

In the absence of clear evidence, we are forced to make guesses about which of the patterns have been internalised by a language user and which of the patterns are simply accidental correlations in the corpus. As soon as clear evidence from psycholinguistic experimentation on the storage, recognition and production of linguistic forms becomes available, we must be willing to revise our initial guesses on the basis of new evidence.

In their introductory text on Classical Generative Phonology, Kenstowicz and Kisseberth (1979: 154, 232) lament that the analyses of the languages which they present, are based almost entirely on internal evidence. They acknowledge that the lack of external evidence raises serious questions as to the psychological validity of the analyses presented. In short, there are those who affirm that external evidence, and not internal evidence, will ultimately reveal what theoretical constructs are psychologically real (Derwing, Prideaux, and Baker 1980: 6; Itkonen 1978: 85; Wheeler 1980: 65).

Perhaps the best stance to take on this issue is that all evidence is good and useful, but that some types are simply more telling of cognitive processing. Internal evidence is ambiguous to interpret in mentalistic terms, while experimental evidence is less so in that it can be refined with experimental controls (Ohala cited by Fromkin 1980: 21011). Nevertheless, internal evidence is relevant to the search for psychological reality in that it determines what structures exist in the language, and are thus available to be potentially internalized by the speakers of the language.

In this section, several arguments have been presented which demonstrate why there is doubt as to the reality of many phonological theories, while at the same time, people are apt to believe that the theoretical constructs of other sciences are real. One may not understand the difference between empirical and nonempirical sciences, or between internal and external evidence, or understand what autonomous linguistics is. Nevertheless, it is clear that there are large differences between facts and evidence in chemistry or astronomy, and facts and evidence in much of what goes on in phonology. One does not need to look closely to see that there is a wide discrepancy between the way phonological theories are proven true, and the way theories in the empirical sciences are proven true.

Phonological theorizing is carried out and proven real in a very different manner than other sciences which claim to have mentalistic import. Therefore, when phonologists are asked for convincing evidence for the psychological significance of their theories, they are in essence, being asked for evidence which is recognizably psychological in nature, as well as evidence which is gathered by empirical means. Once these theories are determined, tested and proven in such a way, there will be fewer calls for better evidence, and fewer charges that the theories are not necessarily psychologically relevant.

3. The relationship between formal and empirical analyses. Most contemporary phonological analyses are formal analyses. Formal analyses are primarily based on in- 
ternal evidence, utilize autonomous methodologies, and are nonempirical in nature. Empirical approaches contrast with formal approaches in that they make use of both internal and external evidence, are empirical by definition, and are carried out by means of nonautonomous methods.

Many of those who argue that there is a difference between formal and empirical linguistics, make the distinction in order to illustrate how an empirical analysis is much more justified in making mentalistic claims than a formal analysis. Aside from that, few elevate one approach over another, In fact, many who make the differentiation, state that both types of linguistic research are useful and worthwhile, and that there are important questions to be answered in both fields (Carr 1990; Hutchinson 1974: 73; Itkonen 1976: 6; Kac 1992: 54-7; Katz 1981, 1985; Lass 1976a: 220).

However, the problem which is cited is that the domains of both approaches are not kept separate. The principle cause of this is the desire to provide a unified account of both the structure of a language, as well as what knowledge speakers have of the language. This position is exemplified in Chomsky's writings. On the one hand, he asserts that generative linguistics is the study of abstract linguistics entities. At the same time, he proposes that it is the empirical study of human cognitive abilities (Katz and Postal 1991: 541-47; Olshewsky 1985). Katz (1985: 193) illustrates why this position is untenable:

No one confuses psychological theories of how people make inferences with the logical theories of implication, or psychological theories of how people perform arithmetical calculations with mathematical theories of numbers. Yet, in the exact parallel case of linguistics, conceptualists do not make the distinction, conflating a psychological theory of how people speak and understand speech with a theory of the language itself.

Conflation of the two domains is responsible for the practice of carrying out an analysis in one approach, and then making claims which correspond to the domain of the other. An example of how a phonological analysis is accomplished will be helpful in illustrating this point.

Suppose that a phonologist goes about analyzing a pattern found in a language within a formal approach. The phonologist, unlike the native speaker, may have knowledge of the history of the language to be analyzed, as well as what goes on in the phonologies of related languages. S/he also is aware of what sort of patterns are common and uncommon in languages of the world, as well as what phones constitute natural classes. The task is undertaken in accordance with various formal principles; the phonologist seeks to provide an analysis which is elegant and simple, and which accounts for the greatest number of lexical items. Such an analysis, which includes principles of universal grammar, and has independent motivation is more highly valued than one that does not. Of course what this analysis claims to account for is the language of an idealized speaker-hearer.

Up until this point, this is a perfectly valid method carried out within a formal approach, and there has been no intermingling of formal and empirical domains. This analysis may legitimately claim to capture the phonological pattern or structure it in- 
tends to. As a result, it is a valid analysis of the language phenomenon. However, what often occurs is that empirical claims are ascribed to formal analyses. Any of the following claims is empirical in nature, and if used in conjunction with an analysis such as the one described above, would constitute an improper mixture of formal and empirical approaches: 1) the analysis is empirical; 2) the analysis is descriptively adequate, that is, it is not simply valid as a description of the data on which it was based, but it represents the knowledge that actual speakers have of their language.

The fact that an alternation, constraint, or structure can be found and described utilizing formal methodology, is not grounds for supposing that it is somehow represented in native speakers' minds, nor that they have any sort of conscious or tacit knowledge of it. Phonologists have arrived at many creative and elegant analyses of phonological phenomena, but in many cases, it is still to be seen which of these are captured by native speakers, which are the leftovers of diachronic phonological or morphological changes, and which have synchronic psychological relevance.

If formal and empirical approaches are both valid ways of approaching linguistic questions, then why is it necessary to distinguish between the two? The answer is that invalid conclusions are reached when the two are confused (Yngve 1986). The first step towards resolving this problem is recognizing that there are indeed two approaches (Prideaux 1971:346). One must make a choice between determining what would be the ideal phonological system of an ideal speaker-hearer, and determining what real speakers actually know about their language, as well as how they actually produce and comprehend it. ${ }^{4}$

Accordingly, a good analysis is one which recognizes the domain to which it belongs, the methods and criteria which are valid in that domain, and which does not make claims outside of its domain. For example, the results of a psycholinguistic probe into how native speakers utilize a certain phonological pattern, should not have any bearing on what would be the most rigorous, concise, or elegant way to account for that pattern in a given formal framework. Conversely, the most intuitively valid formulae for describing a pattern are to be ascribed only to the ideal speaker-hearer, not necessarily to actual speakers of the language.

The emphasis on keeping formal and empirical approaches separate does not mean that there is not, or should not be, an interface between them. Theory which never goes beyond the theoretical stage is just as uninsightful as data gathering and experimentation carried out with complete disregard to theoretical underpinnings. Clearly stated theory should naturally lead to, and precede empirical research. In the case of linguisset forth in Chomsky and Halle (1968) were employed by Otero (1971) to depict the phonological evolution of Spanish from Latin. Hartman (1981) has developed a computer program based on Otero's rules which derives Spanish words from Latin words. This program serves as a valuable research tool which can be used to test theories about diachronic Spanish linguistics. If it were not for the formal notations of classical generative phonology it is very unlikely that it would have been possible to develop this tool. 
tics, formal theories should serve as the basis for empirical investigation (Baker 1979: 141; Black and Chiat 1981: 51-4; Derwing 1979: 125; Kac 1980: 243).

4. Conclusions. Many phonological theories claim to be relevant to linguistic cognition. However, the steps in a phonological derivation are not thought to mirror the actual algorithms which are utilized in the course of speech comprehension and production. Instead, the rules and representations are considered to be an abstract representations of speakers' underlying knowledge of their language.

There are two senses in which an analysis may be considered psychologically real. In the strong sense, it is real if the steps in the derivation have counterparts in actual language production or comprehension. This, of course, is not what the steps in a phonological derivation profess to represent. Therefore, an analysis may only be psychologically real in the weak sense of the word.

A grammar is real in the weak sense if the outcome of the grammar corresponds to the output and intuitions of the speakers of the language. This means that phonological rules, orderings, and representations are not real. What are potentially real are the structures and generalizations which the rules are designed to account for.

Although phonological entities have the potential of being real in the weak sense, their psychological validity has been questioned on a number of different grounds. The first has to do with the truth versus reality issue. This questions the supposition that the best formal analysis of a phenomenon is necessarily a psychologically significant analysis also. If the best formal theory is taken to be necessarily real, then there is no way to distinguish between theoretical constructs which may have psychological validity, and those which are merely notational artifacts. An analysis may reveal many phonological patterns, but their existence does not necessarily imply that they are significant for the speakers of the language.

A second reason why the reality of many analyses is doubted is that most contemporary approaches to phonology are nonempirical. That is, they are not stated in such a way as to make them subject to potential falsification based on events which take place in space and across time. The reality of entities belonging to the nonempirical sciences is questionable in comparison to the reality of entities of the empirical sciences. This is true because the empirical sciences deal with entities which are proves and disproved with recourse to spatiotemporal events. Theoretical entities which escape possible falsification in space and time are not likely to exist in space or time either. Of course, the existence of a given phonological phenomenon is falsifiable on the basis of a corpus of utterances. However, its psychological status must be determined separately.

In order to determine whether a linguistic phenomenon is psychologically valid, it needs to be verified by psychological means. Therefore, the third reason for doubting the psychological validity of phonological theories is that many are established with little or no recourse to the speakers of the language via experimental psychology.

The fourth cause of skepticism is that most phonological analyses are founded on an extremely narrow base of evidence. Internal evidence such as internal reconstruc- 
tion, data gleaned from a corpus of utterances, and carefully monitored speech are the principle sources of evidence upon which contemporary analyses are typically based. External evidence, as found in speech errors, language games, and psycholinguistic experimentation, is more often than not overlooked, or at least not commonly sought. However, external evidence appears to be more telling of what speakers know about their language than internal evidence, since it involves actual language use and manipulation. Therefore, a claim regarding the psychological significance of a phonological analysis is strengthened if it is supported with external, as well as internal evidence. There is also a need for such evidence in order to avoid circular argumentation. Circular argumentation occurs when the observations which form the basis for assuming the existence of a theoretical entity, are at the same time, used as proof of the existence of the entity.

In summary, phonological analyses are often assumed to be psychologically significant. However, there are many grounds for challenging this assumption. This is not to say that some aspects of the theory may well be psychologically real. Phonological analyses attempt to codify linguistic systems. These systems exist in the minds of language speakers and have somehow been codified by them. Therefore, it is highly possible that there is some correspondence between an analysis and the actual knowledge that speakers have about their language. The charge is simply that most are based on evidence which is not empirical, and which is obtained by means which are not recognizably psychological. Once phonological theories are established in this manner, their psychological validity will be challenged less often.

\section{References}

Baker, William J. (1979). On draining the conceptual swamp. In Perspectives in Experimental Linguistics, Gary D. Prideaux (ed.), 141-149. Amsterdam: John Benjamins.

Bertinetto, Pier Marco (1992). The use and misuse of external evidence in phonology. In Phonologica 1988, Wolfgang U. Dressler, Hans C. Luschützky, Oscar E. Pfeiffer, and John R. Rennison (eds.), 33-47. Cambridge: Cambridge University Press.

Black, Maria, and Shulamuth Chiat (1981). Psycholinguistics without 'psychological reality.' Linguistics 19, 37-61.

Botha, Rudolf P. (1971). Methodological Aspects of Transformational Generative Phonology. The Hague: Mouton.

. (1973). The Justification of Linguistic Hypotheses. The Hague: Mouton.

(1989). Challenging Chomsky. Oxford: Basil Blackwell.

Bresnan, Joan, and Ronald M. Kaplan (1982). Introduction: Grammars as mental representations of language. In The Mental Representation of Grammatical Relations, Joan Bresnan (ed), xvii-lii. Cambridge, Mass.: MIT Press.

Campbell, Lyle (1979). The quest for psychological reality: External evidence in phonology. In Proceedings of The Ninth International Congress of Phonetic Sciences, 
vol. 2, Eli Fischer-Jørgensen, Jørgen Rischel, and Nina Thorsen (eds.), 74-8. Copenhagen: University of Copenhagen.

(1986). Testing phonology in the field. In Experimental Phonology, John J.

Ohala and Jeri Jeager (eds.), 163-73. Orlando: Harcourt Brace Jovanovich.

Carr, Philip. (1990). Linguistic Realities: An Autonomist Metatheory for the Generative

Enterprise. Cambridge: Cambridge University Press.

Chomsky, Noam (1964). Current Issues in Linguistic Theory. The Hague: Mouton.

. (1972). Language and Mind. New York: Harcourt Brace Jovanovich.

(1976). On the biological basis of language capacities. In The Neuropsy-

chology of Language, R. W. Rieber (ed.), 1-24. New York: Plenum Press.

(1980a). Rules and Representations. New York: Columbia University Press.

(1980b). Rules and representations. In The Behavioral and Brain Sciences

3.1-15, 42-61.

. (1981). Lectures on Government and Binding. Dordrecht: Foris.

(1982). The Generative Enterprise. Dordrecht: Foris.

(1986). Knowledge of Language. New York: Praeger.

Chomsky Noam, and Morris Halle (1968). The Sound Pattern of English. New York:

Harper and Row.

Cutler, Anne (1979). The psychological reality of word formation and lexical stress rules. In Proceedings of The Ninth International Congress of Phonetic Sciences, vol. 2, Eli Fischer-Jørgensen, Jørgen Rischel, and Nina Thorsen (eds.), 79-85. Copenhagen: University of Copenhagen.

Derwing, Bruce L. (1973). Transformational Grammar as a Theory of Language Acquisition. London: Cambridge University Press.

. (1979). Psycholinguistic evidence and linguistic theory. In Perspectives in Experimental Linguistics, Gary D. Prideaux (ed.), 113-38. Amsterdam: John Benjamins.

. (1980). Against autonomous linguistics. In Evidence and Argumentation in Linguistics, Thomas A. Perry (ed.), 163-89. Berlin: Walter de Gruyter.

. (1983). On drawing the right conclusions in psycholinguistics: Some critical areas of control in experimental and analytical practice. In Proceedings of the Ninth Annual Meeting of the Berkeley Linguistics Society, Amy Dahlstrom et al. (eds.), 64-73. Berkeley: Berkeley Linguistics Society.

Derwing, B. L., G. D. Prideaux, and W. J. Baker (1980). Experimental linguistics in historical perspective. In Experimental Linguistics, Gary D. Prideaux, Bruce L. Derwing, and William J. Baker (eds.), 1-13. Ghent, Belgium: E. Story-Scientia.

Derwing, Bruce L. and Royal Skousen (1989). Real-time morphology: Symbolic rules or analogical networks? In Proceedings of the Fifteenth Annual Meeting of the Berkeley Linguistics Society, Kira Hall, Michael Meacham and Richard Shapiro (eds.), 48-62. Berkeley: Berkeley Linguistics Society.

Derwing, Bruce L., and William J. Baker (1977). The psychological basis for morphological rules. In Language Learning and Thought, John Macnamara (ed.), 85-110. New York: Academic Press.

Fromkin, Victoria A. (1975). When does a test test a hypothesis, or, what counts as evidence? In Testing Linguistic Hypotheses, David Cohen and Jessica R. Wirth (eds.), 43-64. Washington D. C.: Hemisphere. 
. (1980). The psychological reality of phonological descriptions. In Proceedings of the Ninth International Congress of Phonetic Sciences, vol. 3, Eli Fischer-J rgensen, and Nina Thorsen (eds.), 195-202. Copenhagen: University of Copenhagen.

Goyvaerts, Didier L. (1978). From triumphant euphoria to bitter disappointment? Communication and Cognition 11, 287-307.

Hall, Robert A. Jr. (1987). Linguistics and pseudo-linguistics. Amsterdam: John Benjamins; Reprinted from 1981/82. Review of Newmeyer, Linguistic theory in America. Forum Linguisticum 6, 177-88; and 1973. Journal of English Linguistics $7,21-42$.

Harmon, Gilbert (1980). Two quibbles about analyticity and psychological reality. The Behavioral and Brain Sciences 3, 21-22.

Hartman, Steven Lee (1981). A universal alphabet for experiments in comparative phonology. Computers and the Humanities 15, 75-82.

Hutchinson, Larry G. (1974). Grammar as theory. In Explaining Linguistic Phenomenon, David Cohen (ed.), 43-73. New York: John Wiley.

Itkonen, Esa (1976a). Linguistics and empiricalness: Answers to criticisms. Helsinki: University of Helsinki.

(1976b). The use and misuse of the principle of axiomatics in linguistics. Lingua 38, 185-220.

. (1978). Linguistics: Nonempirical and empirical. In Proceedings of the 12th International Congress of Linguists, Wolfgang U. Dressler and Wolfgang Meid (eds.), 157-8. Innsbruck: University Innsbruck.

. (1983). Causality in Linguistic Theory. London: Croom Helm.

Kac, Michael (1974). Autonomous linguistics and psycholinguistics. Minnesota Working Papers in Linguistics and Philosophy of Language 2, 42-7.

(1980). In defence of autonomous linguistics. Linguistics 50, 243-248.

(1992). Grammars and Grammaticality. Amsterdam: John Benjamins.

Katz, J. J. (1985). An outline of platonist grammar. In The Philosophy of Linguistics, Jerrold J. Katz (ed.), 172-203. Oxford: Oxford University Press.

Katz, Jerrold J. (1981). Language and Other Abstract Objects. Totowa, New Jersey: Rowman and Littlefield.

Katz, Jerrold J., and Paul M. Postal. (1991). Realism vs. conceptualism in linguistics. Linguistics and Philosophy 14, 515-554.

Kenstowicz, Michael, and Charles Kisseberth (1979). Generative Phonology. San Diego: Academic Press.

Lass, Roger (1976a). English Phonology and Phonological Theory. London: Cambridge University Press.

. (1976b). On generative taxonomy and whether formalisms 'explain'. Studia Linguistica 30, 139-154.

. (1984). Phonology: An Introduction to Basic Concepts. Cambridge: Cambridge University Press.

Linell, Per (1976). Is linguistics an empirical science? Studia Linguistica 30, 77-94.

Matthews, Robert J. (1991). Psychological reality of grammars. In The Chomskyan Turn, Asa Kasher (ed.), 182-99. Cambridge, Mass.: Basil Blackwell.

Mohanan, K. P. (1986). The Theory of Lexical Phonology. Dordrecht: D. Reidel. 
Morin, Yves-Charles (1988). Morphological conditioning in phonologically transparent processes: Evidence from the evolution of vowel reduction in Vinzelles Occitan.

Canadian Journal of Linguistics 33, 431-42.

Ohala, John J. (1974). Experimental historical phonology. In Historical Linguistics II, J. M. Anderson, and C. Jones (eds.), 353-389. Amsterdam: North Holland. (1990). There is no interface between phonology and phonetics: A personal view. Journal of Phonetics 18, 153-171.

Olshewsky, Thomas. (1985). Chomsky's realism. Proteus 2, 19-25.

Otero, Carlos-Peregrín (1971). Evolución y Revolución en Romance. Barcelona: Seix Barral.

Popper, Karl R. (1968). The Logic of Scientific Discovery. 2nd ed. New York: Harper and Row; original English edition 1959, London: Hutchinson.

Prideaux, Gary (1971). On the notion 'linguistically significant generalization.' Lingua $26,337-347$.

(1980). rejection of autonomous linguistics. Linguistics 50, 245-247.

Ringen, Jon D. (1975). Linguistic facts: A study of the empirical scientific status of transformational generative grammars. In Testing Linguistic Hypotheses, David Cohen, and Jessica R. Wirth (eds.), 1-42. Washington: Hemisphere.

Rischel, Jørgen (1978). Some general remarks in realism in current phonological work.

In Papers from the Fourth Scandinavian Conference of Linguistics, Kirsten Gregersen, Hans Basbøll, and Jacob Mey (eds.), 419-31. Odense: Odense University Press.

Skousen, Royal (1975). Substantive Evidence in Phonology. The Hague: Mouton. (1989). Analogical Modeling of Language. Dordrecht: Kluwer Academic Publishers.

Spence, Kenneth W. (1956). Behavior Theory and Conditioning. New Haven: Yale University Press.

Stemberger, Joseph Paul. 1994. Rule-less morphology at the phonology-lexicon interface. In The Reality of Linguistic Rules, Susan D. Lima, Roberta L. Corrigan, and Gregory K. Iverson (eds.), 147-169. Amsterdam: Benjamins.

Steinberg, Danny D. (1975). Chomsky: From formalism to mentalism and psychological invalidity. Glossa 9, 218-52.

Wheeler, Cathy J. (1980). On the relationship between phonology and psychology. Papers in Linguistics 13, 51-100.

Yngve, Victor H. 1986. Linguistics as a Science. Bloomington and Indianapolis: Indiana University Press.

Zimmer, Karl E. (1969). Psychological correlates of some Turkish morpheme structure conditions. Language 45, 309-321.

Zwicky, Arnold M. (1975). The strategy of generative phonology. In Phonologica 1972, Wolfgang U. Dressler, and F. V. Marks (eds.), 151-165. Salzburg: Wilhelm Fink. 
Sestavek se sprašuje, ali je večina predloženih fonoloških analiz sploh psihološko relevantnih. Razlogi za tovrstne dvome so štirje: 1 . Teoretična ustreznost še ne vodi nujno k psihološki pomenljivosti. 2. Večina pristopov ni izkustvenih, kajti teorije ne podvržejo možni prostorsko-časovni preveri. 3. Fonološke teorije se poenostavljajo na podlagi malo ali nič eksperimentalnopsihološkega dela z govorci jezika. 4. Nadaljnji razlog za dvome je pičlost dokazil, na katerih temelji večina analiz.

Čeprav torej večine teoretičnih analiz ne moremo šteti med psihološko pomenljive, jih vendar obravnavamo kot prvi korak na poti k psihološko veljavnim analizam. Ko bodo fonološke analize osnovane na izkustvenih podatkih, pridobljenih s sredstvi psihologije, psihološke veljavnosti takih analiz ne bodo več tolikokrat postavljali pod vprašaj. 